Top Magn Reson Imaging. 2010 October ; 21(5): 291-296. doi:10.1097/RMR.0b013e31823dfe2e.

\title{
Imaging Cartilage Physiology
}

\author{
Arijitt Borthakur, PhD and Ravinder Reddy, PhD \\ Center for Magnetic Resonance \& Optical Imaging, Department of Radiology, University of \\ Pennsylvania School of Medicine
}

\section{INTRODUCTION}

Imaging the physiology of cartilage tissue holds promise for an early detection of osteoarthritis (OA), the most common joint disease whose prevalence will only increase due to an aging population (1). The disease is characterized by focal cartilage damage, changes in the subchondral bone, mild synovitis, and thickening of the joint capsule in synovial joints. Key to understanding the pathology of the disease is to appreciate that the biochemistry of cartilage tissue underlies its special purposes of control over joint loading and motion. Only a small fraction of the volume of cartilage is occupied by cells (chondrocytes) that facilitate construction, repair and degradation of the extracellular matrix (ECM) in response to stimuli. Water occupies $70 \%$ of the volume of the ECM (1) while the major solid constituents (Figure 1) are aggrecan (5\% w/v) and type II collagen $(20 \% \mathrm{w} / \mathrm{v})$.

The early stage of $\mathrm{OA}$ is associated with an increase in enzymatic degradation by matrix metalloproteinases resulting in glycosaminoglycan (GAG) aggrecan depletion and degradation of the collagen network. In cartilage, GAG side chains are made of continuously repeating disaccharides containing carboxyl and sulfate functional groups and are both negatively charged under physiological conditions. The negative charge GAG confers on cartilage is the fixed charge density (FCD). Gorton originally proposed a model for the physiology of connective tissues in which a high polysaccharide content induces an osmotic pressure that is resisted by the network of collagen (5). In this model, the presence of highly electronegative and immobile GAG macromolecules results in an influx of sodium ions to maintain electro-neutrality. Since then, Maroudas extended this model by introducing the Donnan equilibrium to describe the flux of charged ions across a semi-permeable membrane in the presence of a charged but non-exchanging GAG restricted to a single compartment $(6,7)$. In this model, the low hydraulic permeability of GAG counterbalances resistive loads by its swelling pressure while collagen provides tensile and shear strength. Therefore, GAG loss in early OA initiates a cascade by which osmotic pressure is reduced and joint compression permanently disrupts the cartilage leading to thinning, fracturing and subsequently pain $(8,9)$.

Radiographic imaging is the current gold standard in imaging technology to detect advanced stages of OA. Lacking sensitivity to soft tissues, this x-ray based technique measures joint space narrowing (JSN) to indirectly gauge the extent of damage to cartilage. In addition,

Address for Correspondence: Ari Borthakur, PhD Assistant Professor, Department of Radiology Associate Director, Center for Magnetic Resonance \& Optical Imaging University of Pennsylvania School of Medicine B1 Stellar-Chance Laboratories 422 Curie Boulevard Philadelphia, PA 19104-6100 Tel: (215) 573-8482 Fax: (215) 573-2113 borthaku@ upenn.edu Web: http://med.cmroi.upenn.edu.

This is a PDF file of an unedited manuscript that has been accepted for publication. As a service to our customers we are providing this early version of the manuscript. The manuscript will undergo copyediting, typesetting, and review of the resulting proof before it is published in its final citable form. Please note that during the production process errors may be discovered which could affect the content, and all legal disclaimers that apply to the journal pertain. 
outcome instruments for assessment of OA in patients such as the Knee Injury and Osteoarthritis Outcome Score (KOOS), an extension of the Western Ontario and McMaster Universities Osteoarthritis Index (WOMAC), is also used to determine mobility and pain in a specific joint $(2,3)$. However, radiography, along with nuclear medicine scans, arthrography, and computed tomography (CT) scans, are limited in their use because they are unable to detect early cartilage abnormalities (4). Conventional $\mathrm{T}_{1}$ and $\mathrm{T}_{2} \mathrm{MRI}$ can directly visualize all diarthrodial tissues, including cartilage, bone, synovium, menisci, and ligaments and has substantial advantages over radiography (10-12). Due to the high morbidity of OA, therapeutic interventions are particularly necessary but current methods are restricted to management of pain and surgical interventions (13). However, improving outcomes require development of more effective interventions that can slow or reverse the course of the disease. In this context, there is a requirement for strong diagnostic information sensitive to the early stages of the disease, where cartilage appears intact on radiographs.

The aim of this review is to highlight new MRI-based techniques that exploit spin dynamics between endogenous macromolecules of cartilage. These include $T_{1_{\rho}}$ and $T_{2}$ relaxometry, Chemical Exchange Saturation Transfer (CEST), Magnetization Transfer (MT), all protonbased MRI techniques, and sodium MRI. Most of these techniques have been developed to specifically detect the GAG component of cartilage, which is the more important element due to the ostensibly limited contribution of collagen to the initiating steps of OA (14). Only the salient features of these methods are described here with a limited literature review. The reader is referred to specialized reviews on each topic described.

\section{$T_{1} \rho$ Relaxometry}

$\mathrm{T}_{1_{\rho}}$ MRI is an alternative to conventional $\mathrm{T}_{1}$ and $\mathrm{T}_{2}$ MRI (15) by its use of a long-duration, low-power radiofrequency (RF) referred to as spin-lock (SL) pulse applied to the magnetization in the transverse plane. The magnetization is effectively spin-locked around an effective $B_{1}$ field created by the vector sum of the applied $B_{1}$ and any off-resonant component. The spin-locked magnetization will relax with a time constant $T_{1_{\rho}}$, the spinlattice relaxation in the rotating frame, during the RF field. The $\mathrm{B}_{1}$ field attenuates the effect of dipolar relaxation, static dipolar coupling, chemical exchange and background gradients on the signal resulting in a $T_{1}$ that is always greater than $T_{2}$. $T_{1 \rho}$ is influenced by the exchange of hydroxyl $(-\mathrm{OH})$ and amide $(-\mathrm{NH})$ protons on the PG side-chain (16).

Quantitative $\mathrm{T}_{1_{\rho}}$ MRI relaxation maps (relaxometry) reflecting the biochemical composition of cartilage are created by fitting the signal intensity of $\mathrm{T}_{1 \rho}$ weighted MR images as a function of the duration of the SL pulse while the amplitude of SL pulse $\left(\gamma \mathrm{B}_{1} \sim 0.1-\mathrm{few} \mathrm{kHz}\right)$ is fixed (15). In this manner, spatial maps of $T_{1}$ values related to macromolecular composition of tissues can be visualized and analyzed. There has been considerable amount of work on biological tissues using $\mathrm{T}_{1}$-spectroscopy and imaging dealing with tumors, muscle, myocardium, blood flow and cartilage (17-27).

Several studies had reported that the non-averaged dipolar interaction between water protons associated with collagen is the predominant contributor to relaxation in cartilage (28). $\mathrm{T}_{1_{\rho}}$ dispersion MRI, where the amplitude of the SL pulse amplitude is also varied, can be used to detect spectral density components in cartilage that are in the neighborhood of $\gamma \mathrm{B}_{1}$. The effect of spin-locking reduces the laminar appearance in cartilage as demonstrated by Akella et al in an orientation-dependent MRI experiment of cartilage plugs (29). In this study, a typical laminar appearance was present in $\mathrm{T}_{2} \mathrm{MRI}$ when the normal to the surface of cartilage was parallel to $B_{0}$ but absent in $T_{1}$ MRI of the same cartilage specimen. In addition, $T_{1}$ values were consistently greater than $T_{2}$ at all orientations throughout the cartilage layers, a result of spin-locking the magnetization. 
Several studies have demonstrated the efficacy of $T_{1}$ MRI in detecting early tissue pathology with increasing values in OA-affected cartilage compared to normal tissue (30). $\mathrm{T}_{1}$ MRI was also demonstrated to quantitatively evaluate meniscus and cartilage matrix in animal models as well as in patients with acute anterior cruciate ligament (ACL) injuries $(31,32)$. Studies on arthroscopically-confirmed early grades of chondromalacia have demonstrated the potential of $\mathrm{T}_{1}$ mapping method in detecting earliest molecular changes in cartilage in vivo (33). Recently, a multicenter study of OA subjects has shown that larger changes were observed in $\mathrm{T}_{1_{\rho}}$ compared to $\mathrm{T}_{2}$, cartilage volume, and thickness measurements (34) however, the reproducibility of $T_{2}$ relaxometry was better than $T_{1 \rho}$.

\section{$T_{2}$ Relaxometry}

The spin-spin relaxation time $\left(\mathrm{T}_{2}\right)$ has been shown to be sensitive to the water content and the concentration and anisotropic organization of type II collagen in cartilage (35). $\mathrm{T}_{2}$ has been shown to decrease from $\sim 70 \mathrm{~ms}$ measured in the superficial articular surface of cartilage to $\sim 30 \mathrm{~ms}$ in the sub-chondral (36) possibly as a result of the change in collagen structure and orientation through the depth (Figure 3). The orientation dependence of $\mathrm{T}_{2}$ (i.e. $\mathrm{T}_{2}$ anisotropy) stemming from static dipolar interaction between water molecules associated with oriented collagen has been clearly demonstrated in cartilage plugs imaged at high field (28). Several laminae are visible corresponding to the physiologic zones of different collagen fiber orientations in the tissue. While $\mathrm{T}_{2}$ mapping can be readily performed even online on some of the newer MRI scanners, its potential for detecting early OA, particularly its sensitivity to PG depletion, remains inconclusive $(37,38)$.

\section{MT MRI}

Magnetization Transfer (MT) MRI is a method of indirectly detecting macromolecules in cartilage by exploiting the chemical exchange phenomenon between 'free' water and water 'bound' to collagen (39). MRI is performed by off-resonance $(\Delta v \sim 2-10 \mathrm{kHz})$ saturation of the broad bound spins and observing the decrease in the narrow free water signal (40-43). MT contrast is mediated by the dipolar cross relaxation and exchange rate and relative fractions of the bound and free water fractions. The MT effect is visible on a 'z-spectra', where the longitudinal magnetization of the free water is plotted as a function of the frequency offset of the saturation pulse. MT MRI is primarily sensitive to the content and orientation of collagen and is not sensitive to GAG in cartilage (44). While quantitative MT MRI is restricted primarily to basic research studies, MT ratio (MTR) imaging is used in clinical research since this method computes a quantitative difference image acquired with and without off-resonance saturation and can be performed within a reasonable scan time (45).

\section{CEST MRI}

Chemical Exchange Saturation Transfer is a method to directly detect exchangeable solute protons in tissues by constant irradiation and saturation of their chemically shifted magnetization $(46,47)$. The CEST signal is detected as a reduction in the water signal after the saturated spins undergo chemical exchange with water (48), provided the exchange is more rapid than the $T_{1}$ of either site. The asymmetric distribution of labile protons around the central water peak in cartilage is readily detected in the difference image obtained after saturating symmetrically on either side of the water. A very homogeneous $\mathrm{B}_{0}$ is necessary for a robust estimation of the difference signal. Furthermore, care must also be taken to avoid the direct saturation of the water peak due to the close resonances of labile species of interest.

In spite of these stringent requirements, solutes in the nanomolar to millimolar range have been reliably detected using this approach in vitro $(49-52)$ and in vivo $(53,54)$. The 
feasibility of CEST MRI to reliably detect GAG in vivo was recently demonstrated in cartilage of the knee joint (55) by comparing it with sodium MRI of the same joint (Figure 4). However, the 'gagCEST' approach (56) should be limited to high field scanners such as $7 \mathrm{~T}$ since $-\mathrm{OH}$ protons $\mathrm{n}$ cartilage are only $1 \mathrm{ppm}$ downfield from the water resonance and exchange at a rate of $\sim 1000 \mathrm{~s}^{-1}$ (57). Hence, the $-\mathrm{OH}$ chemical shift is only $129 \mathrm{~Hz}$ at $3 \mathrm{~T}$ and CEST MRI would introduce a substantial direct water saturation. Further, the slow to intermediate exchange limit (i.e. chemical shift between exchanging site and water, $\Delta \omega>$ exchange rate, $\mathrm{k}$ ), required for optimal CEST effect is not fulfilled in the case of -OH protons at 3T. However, at 7T and higher fields, the larger frequency separation of $-\mathrm{OH}$ resonance from water fulfills both the $(\Delta \omega>\mathrm{k})$ condition and also reduces the direct water saturation effect. These factors enable a more reliable quantification of GAG at 7T using the gagCEST approach (55).

\section{${ }^{23} \mathrm{Na}$ MRI}

Several groups have demonstrated feasibility of sodium MRI in the detection of cartilage degeneration in OA (58-62). As a spin-3/2 nucleus with a non-zero quadrupolar moment, ${ }^{23} \mathrm{Na}$ exhibits bi-exponential relaxation in tissues, i.e. fast and slow components of $\mathrm{T}_{2}$ and $\mathrm{T}_{2} *(63,64)$. In cartilage, the negative charge on GAG side-chains attracts $\mathrm{Na}+$ ions (65). Under normal concentrations in cartilage $(\sim 300 \mathrm{mM})$ sodium produces an osmotic gradient that results in a swelling pressure in cartilage $(6,7)$. These findings were based on the fact that Donnan equilibrium holds for cartilage equilibrated in very dilute solutions (66). The loss of the PG during the early onset of OA lowers FCD, thereby reducing [Na] and osmotic pressure in the tissue providing the rationale for sodium MRI as a biomarker for cartilage pathology.

The gyromagnetic ratio $(\gamma)$ of ${ }^{23} \mathrm{Na}$ requires 4 -fold stronger gradients in order to obtain sodium images of equal pixel size to that of conventional proton MRI. Consequently, sodium MRI pulse sequences are forced to image at a long echo time (TE) of $\geq 2 \mathrm{~ms}$, which is deleterious due to the short $\mathrm{T}_{2}$ of sodium in tissues. For this reason radial imaging strategies have been employed to decrease TE $(<200 \mu s)$ to enable sodium MRI with high SNR (67). Sodium in cartilage is under the influence of a non-isotropically or incompletely averaged quadrupolar interaction, which leads to biexponential relaxation rates and the generation of multiple quantum coherences (68). Several groups have studied sodium in biological tissues using multiple quantum filtered (MQF) NMR (69,70). While sodium MQF signal is more sensitive to the macromolecular content and arrangement in the extracellular matrix, it is at best an order of magnitude less in amplitude than the conventional singlequantum sodium MRI signal and impractical for routine clinical imaging (15). Sodium MRI has been implemented on clinical MRI systems to map [Na] in the human knee joint (Figure 5 ), where higher fields (7T and greater) produce higher quality images. However, in spite of these efforts, sodium MRI is still a long ways away from being a clinical tool for the diagnoses of early OA due to inherently low SNR and the requirement for special hardware.

\section{Summary}

MRI based on conventional $\mathrm{T}_{1}$ and $\mathrm{T}_{2}$ contrast is able to provide excellent images of cartilage morphology, but unable to detect changes in cartilage biochemistry and physiology. While OA progression is multi-factorial and slow progressing disease, its early stages involve the breakdown and loss of GAG and collagen from the extracellular matrix. Several MRI-based methods have targeted these macromolecules as markers of disease progression. These include i) $T_{1 \rho}$ relaxometry, a biomarker sensitive to proton exchange between -OH groups in GAG and water but also influenced by collagen, ii) $\mathrm{T}_{2}$ relaxometry that is more related to collagen orientation and tissue hydration, iii) MT MRI, which is sensitive to large macromolecules such as collagen by measuring the effect of off-resonance 
saturation of the exchanging protons between collagen and water, iv) CEST MRI, similar to MT but sensitive to -OH group in GAG, and v) sodium MRI, which despite lower sensitivity, highly specific to GAG content.

These are some of the most promising non-invasive technologies available for detecting early cartilage degeneration. While restricted to research, these methods have been applied to clinical research by several groups and indeed show promise in evaluating OA in humans by demonstrating their sensitivity and specificity to cartilage physiology and biochemistry as well as the ability to detect progression of the disease. In order for these methods to be translated to clinical practice, larger multi-center studies will be required to develop standard protocols, determine grading schemes, and ultimately establish the utility of these methods.

\section{Acknowledgments}

This work was performed at a NCRR supported Biomedical Technology Research Center (P41RR002305).

\section{REFERENCES}

1. Brandt, KD.; Doherty, M.; Lohmander, S. Osteoarthritis. Oxford University Press; Oxford ; New York: 2003. p. xiip. 511

2. Bellamy N, Buchanan WW, Goldsmith CH, Campbell J, Stitt LW. Validation study of WOMAC: a health status instrument for measuring clinically important patient relevant outcomes to antirheumatic drug therapy in patients with osteoarthritis of the hip or knee. J Rheumatol. 1988; 15(12):1833-1840. [PubMed: 3068365]

3. Roos EM, Roos HP, Lohmander LS, Ekdahl C, Beynnon BD. Knee Injury and Osteoarthritis Outcome Score (KOOS)--development of a self-administered outcome measure. J Orthop Sports Phys Ther. 1998; 28(2):88-96. [PubMed: 9699158]

4. Blackburn WD Jr. Chivers S, Bernreuter W. Cartilage imaging in osteoarthritis. Seminars in Arthritis \& Rheumatism. 1996; 25(4):273-281. [PubMed: 8834015]

5. Ogston, A. The biological functions of the glycosaminoglycans. In: Balazs, E., editor. Chemistry and Molecular Biology of the Intercellular Matrix. Vol. Volume 3. Academic Press; New York: 1970. p. 1231-1240.

6. Maroudas AI. Balance between swelling pressure and collagen tension in normal and degenerate cartilage. Nature. 1976; 260(5554):808-809. [PubMed: 1264261]

7. Maroudas, A. Physicochemical properties of articular cartilage. In: Freeman, MAR., editor. Adult articular cartilage. 2nd ed. Pitman Medical; Kent, England: 1979. p. 215-290.

8. Glasson SS, Askew R, Sheppard B, Carito B, Blanchet T, Ma HL, Flannery CR, Peluso D, Kanki K, Yang Z, Majumdar MK, Morris EA. Deletion of active ADAMTS5 prevents cartilage degradation in a murine model of osteoarthritis. Nature. 2005; 434(7033):644-648. [PubMed: 15800624]

9. Stanton H, Rogerson FM, East CJ, Golub SB, Lawlor KE, Meeker CT, Little CB, Last K, Farmer PJ, Campbell IK, Fourie AM, Fosang AJ. ADAMTS5 is the major aggrecanase in mouse cartilage in vivo and in vitro. Nature. 2005; 434(7033):648-652. [PubMed: 15800625]

10. Heron CW. Review article: MRI of the knee. British Journal of Radiology. 1993; 66(784):292302. [PubMed: 8495282]

11. Potter HG, Linklater JM, Allen AA, Hannafin JA, Haas SB. Magnetic resonance imaging of articular cartilage in the knee -An evaluation with use of fast-spinecho imaging. Journal of Bone and Joint Surgery. 1998; 80A(9):1276-1284. [PubMed: 9759811]

12. Recht M, Bobic V, Burstein D, Disler D, Gold G, Gray M, Kramer J, Lang P, McCauley T, Winalski C. Magnetic resonance imaging of articular cartilage. Clin Orthop. 2001; (391 Suppl):S379-396. [PubMed: 11603721]

13. Zhang W, Moskowitz RW, Nuki G, Abramson S, Altman RD, Arden N, Bierma-Zeinstra S, Brandt KD, Croft P, Doherty M, Dougados M, Hochberg M, Hunter DJ, Kwoh K, Lohmander LS, Tugwell P. OARSI recommendations for the management of hip and knee osteoarthritis, Part II: 
OARSI evidence-based, expert consensus guidelines. Osteoarthritis Cartilage. 2008; 16(2):137162. [PubMed: 18279766]

14. Dijkgraaf LC, de Bont LG, Boering G, Liem RS. The structure, biochemistry, and metabolism of osteoarthritic cartilage: a review of the literature. J Oral Maxillofac Surg. 1995; 53(10):11821192. [PubMed: 7562173]

15. Borthakur A, Mellon E, Niyogi S, Witschey W, Kneeland J, Reddy R. Sodium and T1rho MRI for molecular and diagnostic imaging of articular cartilage. NMR Biomed. 2006; 19(7):781-821. [PubMed: 17075961]

16. Duvvuri U, Goldberg AD, Kranz JK, Hoang L, Reddy R, Wehrli FW, Wand AJ, Englander SW, Leigh JS. Water magnetic relaxation dispersion in biological systems: The contribution of proton exchange and implications for the noninvasive detection of cartilage degradation. Proc Natl Acad Sci U S A. 2001; 98(22):12479-12484. [PubMed: 11606754]

17. Santyr GE, Henkelman RM, Bronskill MJ. Spin locking for magnetic resonance imaging with application to human breast. Magn Reson Med. 1989; 12(1):25-37. [PubMed: 2607958]

18. Lamminen AE, Tanttu JI, Sepponen RE, Pihko H, Korhola OA. T1rho dispersion imaging of diseased muscle tissue. Br J Radiol. 1993; 66(789):783-787. [PubMed: 8220948]

19. Dixon WT, Oshinski JN, Trudeau JD, Arnold BC, Pettigrew RI. Myocardial suppression in vivo by spin locking with composite pulses. Magn Reson Med. 1996; 36(1):90-94. [PubMed: 8795026]

20. Charagundla SR, Stolpen AH, Leigh JS, Reddy R. Off-resonance proton T1r dispersion imaging of 17O-enriched tissue phantoms. Magn Reson Med. 1998; 39(4):588-595. [PubMed: 9543421]

21. Mlynarik V, Trattnig S, Huber M, Zembsch A, Imhof H. The role of relaxation times in monitoring proteoglycan depletion in articular cartilage. J Magn Reson Imaging. 1999; 10(4):497-502. [PubMed: 10508315]

22. Grohn OHJ, Kettunen MI, Makela HI, Penttonen M, Pitkanen A, Lukkarinen JA, Kauppinen RA. Early detection of irreversible cerebral ischemia in the rat using dispersion of the magnetic resonance imaging relaxation time, T1rho. J Cereb Blood Flow Metab. 2000; 20(10):1457-1466. [PubMed: 11043908]

23. Poptani H, Duvvuri U, Miller CG, Mancuso A, Charagundla S, Fraser NW, Glickson JD, Leigh JS, Reddy R. T1rho imaging of murine brain tumors at 4 T. Acad Radiol. 2001; 8(1):42-47. [PubMed: 11201456]

24. Duvvuri U, Charagundla SR, Kudchodkar SB, Kaufman JH, Kneeland JB, Rizi R, Leigh JS, Reddy R. Human knee: in vivo T1(rho)-weighted MR imaging at 1.5 T-preliminary experience. Radiology. 2001; 220(3):822-826. [PubMed: 11526288]

25. Borthakur A, Wheaton A, Gougoutas A, Akella S, Regatte R, Charagundla S, Reddy R. In vivo measurement of T1rho dispersion in the human brain at 1.5 tesla. J Magn Reson Imaging. 2004; 19(4):403-409. [PubMed: 15065163]

26. Wheaton A, Dodge G, Borthakur A, Kneeland J, Schumacher H, Reddy R. Detection of changes in articular cartilage proteoglycan by $\mathrm{T}$ (1rho) magnetic resonance imaging. J Orthop Res. 2005; 23(1):102-108. [PubMed: 15607881]

27. Li X, Han ET, Ma CB, Link TM, Newitt DC, Majumdar S. In vivo 3T spiral imaging based multislice T(1rho) mapping of knee cartilage in osteoarthritis. Magn Reson Med. 2005; 54(4):929-936. [PubMed: 16155867]

28. Xia Y, Farquhar T, Burton-Wurster N, Lust G. Origin of cartilage laminae in MRI. Journal of Magnetic Resonance Imaging. 1997; 7(5):887-894. [PubMed: 9307916]

29. Akella S, Regatte R, Wheaton A, Borthakur A, Reddy R. Reduction of residual dipolar interaction in cartilage by spin-lock technique. Magn Reson Med. 2004; 52(5):1103-1109. [PubMed: 15508163]

30. Majumdar S, Li X, Blumenkrantz G, Saldanha K, Ma CB, Kim H, Lozano J, Link T. MR imaging and early cartilage degeneration and strategies for monitoring regeneration. J Musculoskelet Neuronal Interact. 2006; 6(4):382-384. [PubMed: 17185834]

31. Lozano J, Saadat E, Li X, Majumdar S, Ma CB. Magnetic resonance T(1 rho) imaging of osteoarthritis: a rabbit ACL transection model. Magn Reson Imaging. 2009; 27(5):611-616. [PubMed: 19056196] 
32. Bolbos RI, Link TM, Ma CB, Majumdar S, Li X. T1rho relaxation time of the meniscus and its relationship with T1rho of adjacent cartilage in knees with acute ACL injuries at $3 \mathrm{~T}$. Osteoarthritis Cartilage. 2009; 17(1):12-18. [PubMed: 18602280]

33. Witschey W, Borthakur A, Fenty M, Kneeland B, Lonner J, McArdle E, Sochor M, Reddy R. T1rho MRI quantification of arthroscopically confirmed cartilage degeneration. Magn Reson Med. 2010; 63(5):1376-1382. [PubMed: 20432308]

34. Mosher TJ, Zhang Z, Reddy R, Boudhar S, Milestone BN, Morrison WB, Kwoh CK, Eckstein F, Witschey WR, Borthakur A. Knee Articular Cartilage Damage in Osteoarthritis: Analysis of MR Image Biomarker Reproducibility in ACRIN-PA 4001 Multicenter Trial. Radiology. 2011

35. Mosher TJ, Dardzinski BJ. Cartilage MRI T2 relaxation time mapping: overview and applications. Semin Musculoskelet Radiol. 2004; 8(4):355-368. [PubMed: 15643574]

36. Dardzinski BJ, Mosher TJ, Li SZ, VanSlyke MA, Smith MB. Spatial variation of T2 in human articular cartilage. Radiology. 1997; 205(2):546-550. [PubMed: 9356643]

37. Borthakur A, Shapiro E, Beers J, Kudchodkar S, Kneeland J, Reddy R. Sensitivity of MRI to proteoglycan depletion in cartilage: comparison of sodium and proton MRI. Osteoarthritis Cartilage. 2000; 8(4):288-293. [PubMed: 10903883]

38. Nieminen MT, Menezes NM, Williams A, Burstein D. T2 of articular cartilage in the presence of Gd-DTPA2. Magn Reson Med. 2004; 51(6):1147-1152. [PubMed: 15170834]

39. Edzes HT, Samulski ET. Cross relaxation and spin diffusion in the proton NMR or hydrated collagen. Nature. 1977; 265(5594):521-523. [PubMed: 834303]

40. Wolff SD, Balaban RS. Magnetization transfer contrast (MTC) and tissue water proton relaxation in vivo. Magn Reson Med. 1989; 10(1):135-144. [PubMed: 2547135]

41. Wolff SD, Chesnick S, Frank JA, Lim KO, Balaban RS. Magnetization transfer contrast: MR imaging of the knee. Radiology. 1991; 179(3):623-628. [PubMed: 2027963]

42. Lattanzio PJ, Marshall KW, Damyanovich AZ, Peemoeller H. Macromolecule and water magnetization exchange modeling in articular cartilage. Magn Reson Med. 2000; 44(6):840-851. [PubMed: 11108620]

43. Henkelman RM, Stanisz GJ, Menezes N, Burstein D. Can MTR be used to assess cartilage in the presence of Gd-DTPA2-? Magn Reson Med. 2002; 48(6):1081-1084. [PubMed: 12465122]

44. Kim DK, Ceckler TL, Hascall VC, Calabro A, Balaban RS. Analysis of water-macromolecule proton magnetization transfer in articular cartilage. Magnetic Resonance in Medicine. 1993; 29(2): 211-215. [PubMed: 8429785]

45. Stikov N, Keenan KE, Pauly JM, Smith RL, Dougherty RF, Gold GE. Cross-relaxation imaging of human articular cartilage. Magn Reson Med. 2011

46. Ward KM, Aletras AH, Balaban RS. A new class of contrast agents for MRI based on proton chemical exchange dependent saturation transfer (CEST). J Magn Reson. 2000; 143(1):79-87. [PubMed: 10698648]

47. Ward KM, Balaban RS. Determination of $\mathrm{pH}$ using water protons and chemical exchange dependent saturation transfer (CEST). Magn Reson Med. 2000; 44(5):799-802. [PubMed: 11064415]

48. Forsen S, RA H. Study of Moderately Rapid Chemical Exchange Reactions by Means of Nuclear Magnetic Double Resonance. Journal of Chemical Physics. 1963:2892. \&.

49. Aime S, Nano R, Grandi M. A new class of contrast agents for magnetic resonance imaging based on selective reduction of water-T2 by chemical exchange. Invest Radiol. 1988; 23(Suppl 1):S267270. [PubMed: 3198360]

50. Zhang S, Winter P, Wu K, Sherry AD. A novel europium(III)-based MRI contrast agent. J Am Chem Soc. 2001; 123(7):1517-1518. [PubMed: 11456734]

51. Goffeney N, Bulte JW, Duyn J, Bryant LH, van Zijl PC. Sensitive NMR detection of cationicpolymer-based gene delivery systems using saturation transfer via proton exchange. J Am Chem Soc. 2001; 123(35):8628-8629. [PubMed: 11525684]

52. Gilad AA, McMahon MT, Walczak P, Winnard PT, Raman V, van Laarhoven HW, Skoglund CM, Bulte JW, van Zijl PC. Artificial reporter gene providing MRI contrast based on proton exchange. Nat Biotechnol. 2007; 25(2):217-219. [PubMed: 17259977] 
53. Zhou J, Lal B, Wilson DA, Laterra J, van Zijl PC. Amide proton transfer (APT) contrast for imaging of brain tumors. Magn Reson Med. 2003; 50(6):1120-1126. [PubMed: 14648559]

54. van Zijl PC, Jones CK, Ren J, Malloy CR, Sherry AD. MRI detection of glycogen in vivo by using chemical exchange saturation transfer imaging (glycoCEST). Proc Natl Acad Sci U S A. 2007; 104(11):4359-4364. [PubMed: 17360529]

55. Schmitt B, Zbyn S, Stelzeneder D, Jellus V, Paul D, Lauer L, Bachert P, Trattnig S. Cartilage Quality Assessment by Using Glycosaminoglycan Chemical Exchange Saturation Transfer and Na MR Imaging at 7 T. Radiology. 2011

56. Ling W, Regatte R, Navon G, Jerschow A. Assessment of glycosaminoglycan concentration in vivo by chemical exchange-dependent saturation transfer (gagCEST). Proc Natl Acad Sci U S A. 2008; 105(7):2266-2270. [PubMed: 18268341]

57. Schiller J, Naji L, Huster D, Kaufmann J, Arnold K. 1H and 13C HR-MAS NMR investigations on native and enzymatically digested bovine nasal cartilage. Magma. 2001; 13(1):19-27. [PubMed: 11410393]

58. Reddy R, Insko EK, Noyszewski EA, Dandora R, Kneeland JB, Leigh JS. Sodium MRI of human articular cartilage in vivo. Magn Reson Med. 1998; 39(5):697-701. [PubMed: 9581599]

59. Borthakur A, Hancu I, Boada F, Shen G, Shapiro E, Reddy R. In vivo triple quantum filtered twisted projection sodium MRI of human articular cartilage. J Magn Reson. 1999; 141(2):286290. [PubMed: 10579951]

60. Wheaton A, Borthakur A, Dodge G, Kneeland J, Schumacher H, Reddy R. Sodium magnetic resonance imaging of proteoglycan depletion in an in vivo model of osteoarthritis. Acad Radiol. 2004; 11(1):21-28. [PubMed: 14746398]

61. Wang L, Wu Y, Chang G, Oesingmann N, Schweitzer ME, Jerschow A, Regatte RR. Rapid isotropic 3D-sodium MRI of the knee joint in vivo at 7T. J Magn Reson Imaging. 2009; 30(3): 606-614. [PubMed: 19711406]

62. Watts A, Stobbe RW, Beaulieu C. Signal-to-noise optimization for sodium MRI of the human knee at 4.7 Tesla using steady state. Magn Reson Med. 2011

63. van der Maarel JRC. Relaxation of spin $3 / 2$ in a non-zero average electric field gradient. Chem Phys Lett. 1989; 155:288-296.

64. Woessner DE, Bansal N. Temporal characteristics of NMR signals from spin 3/2 nuclei of incompletely disordered systems. Journal of Magnetic Resonance. 1998; 133:21-35. [PubMed: 9654465]

65. Maroudas A, Muir H, Wingham J. The correlation of fixed negative charge with glycosaminoglycan content of human articular cartilage. Biochimica et Biophysica Acta. 1969; 177(3):492-500. [PubMed: 4239606]

66. Urban JPG, Maroudas A, Bayliss MT, Dillon J. Swelling pressures of proteoglycans at the concentrations found in cartilaginous tissues. Biorheology. 1979; 16(6):447-464. [PubMed: 534768]

67. Nielles-Vallespin S, Weber M, Bock M, Bongers A, Speier P, Combs S, Wöhrle J, Lehmann-Horn F, Essig M, Schad L. 3D radial projection technique with ultrashort echo times for sodium MRI: clinical applications in human brain and skeletal muscle. Magn Reson Med. 2007; 57(1):74-81. [PubMed: 17191248]

68. Jaccard G, Wimperis S, Bodenhausen G. Multiple quantum NMR spectroscopy of $S=3 / 2$ spins in isotropic phase: a new probe for multiexponential relaxation. Journal of Chemical Physics. 1986; 85(11):6282-6293.

69. Pekar J, Leigh JS. Detection of bi-exponential relaxation in sodium-23 facilitated by double quantum filtering. Journal of Magnetic Resonance. 1986; 69:582-584.

70. Tanase C, Boada FE. Triple-quantum-filtered imaging of sodium in presence of $\mathrm{B}(0)$ inhomogeneities. J Magn Reson. 2005; 174(2):270-278. [PubMed: 15862244]

71. Mosher TJ, Dardzinski BJ, Smith MB. Human articular cartilage: influence of aging and early symptomatic degeneration on the spatial variation of T2-preliminary findings at $3 \mathrm{~T}$. Radiology. 2000; 214(1):259-266. [PubMed: 10644134]

72. Crema MD, Roemer FW, Marra MD, Burstein D, Gold GE, Eckstein F, Baum T, Mosher TJ, Carrino JA, Guermazi A. Articular cartilage in the knee: current MR imaging techniques and 
applications in clinical practice and research. Radiographics. 2011; 31(1):37-61. [PubMed: 21257932]

73. Staroswiecki E, Bangerter NK, Gurney PT, Grafendorfer T, Gold GE, Hargreaves BA. In vivo sodium imaging of human patellar cartilage with a $3 \mathrm{D}$ cones sequence at $3 \mathrm{~T}$ and $7 \mathrm{~T}$. J Magn Reson Imaging. 2010; 32(2):446-451. [PubMed: 20677276] 


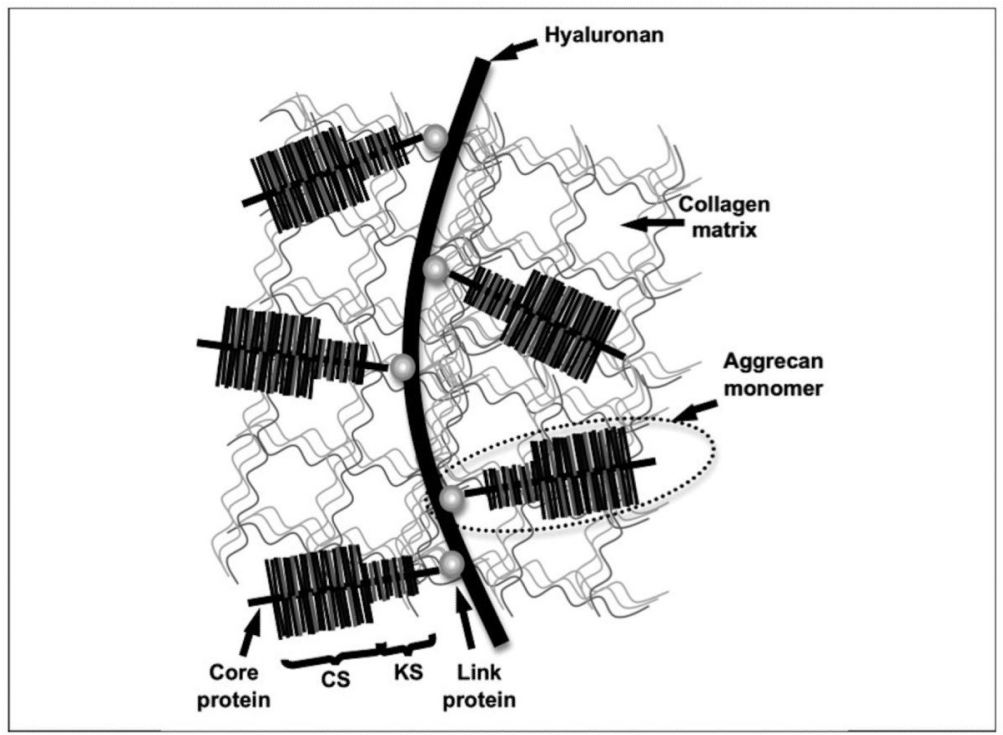

Figure 1.

Schematic of cartilage extracellular matrix (ECM). Sodium is incorporated in to the ECM to balance the fixed charge density (FCD) of negatively charged Chrondroitin Sulfate (CS) and Keratan Sulfate (KS) subgroups of the Aggrecan monomer, the main glycosaminoglycan (GAG) constituent in the ECM. 

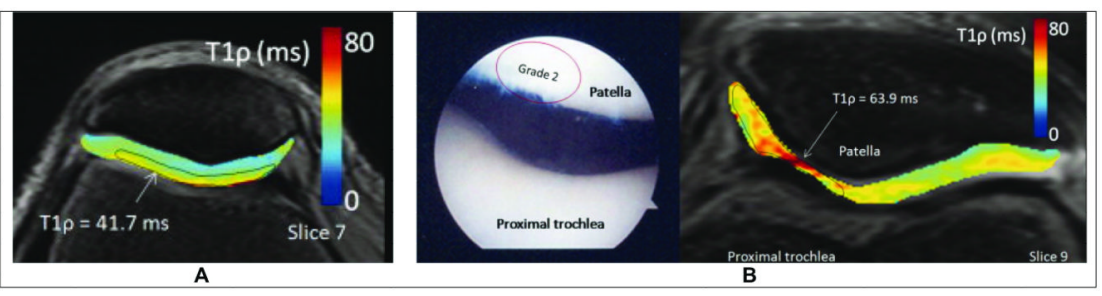

Figure 2.

(A) $\mathrm{T}_{1 \rho}$ relaxation map from a 30 -year-old male with no history of knee injury and no knee pain. Patellar cartilage is homogenously, smoothly varying and has a characteristic increase in $T_{1 \rho}$ from the deep cartilage adjacent to the subchondral bone to the superficial cartilage adjacent to the synovium. The ROI drawn at the cartilage surface had a $T_{1 \rho}=41.7 \mathrm{~ms}$. Arthroscopic photographs (middle panel) and $\mathrm{T}_{1 \rho}$ relaxation map (B) from a 48-year-old male patient observed at arthroscopy to have grade 2 patellar chondromalacia and a torn left medial meniscus, for which a partial medial meniscectomy was performed. Focal elevated medial patellar $\mathrm{T}_{1 \rho}$ was observed with a patellar ROI $\mathrm{T}_{1 \rho}=49.2-62.7 \mathrm{~ms}$ simultaneously with thinning cartilage (33). 

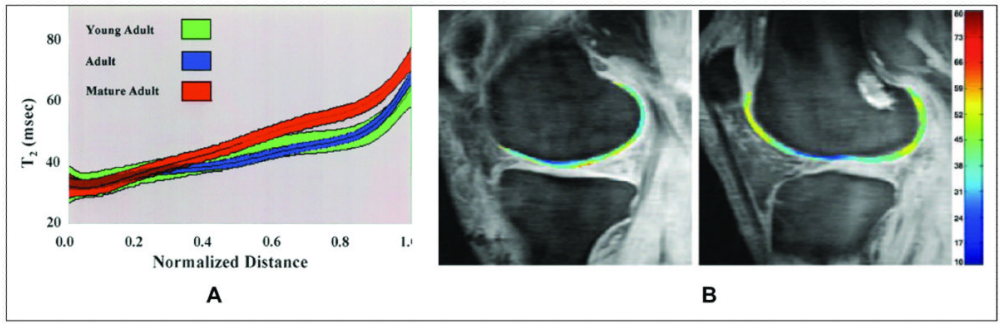

Figure 3.

(A) Variation in $T_{2}$ values with normalized distance from subchondral bone (0.0) to articular surface (1.0) in three age groups (18-30, 31-45, and 45-60 year olds, listed as young adult, adult and mature adult, respectively). The colored areas represent $99.99 \%$ confidence interval of mean $\mathrm{T}_{2}$ along the thickness of cartilage. $\mathrm{T}_{2}$ is related to both collagen and water content, as evident by low and high $\mathrm{T}_{2}$ values, respectively (71). (B) $\mathrm{T}_{2}$ maps obtained in knee cartilage in a 51-year-old man after anterior cruciate ligament repair show higher $\mathrm{T}_{2}$ values (yellow) in the medial (left panel) and lateral (right panel) tibio-femoral compartments, findings indicative of deterioration of the integrity and orientation of the collagen network (72). Color scale is in milliseconds. 


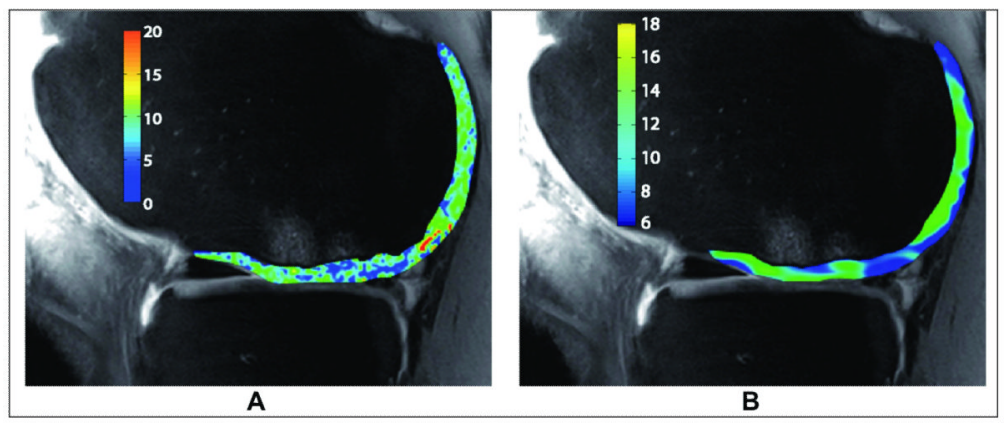

Figure 4.

(A) gagCEST and (B) ${ }^{23} \mathrm{Na}$ images from OA patient's distal femoral cartilage demonstrating correlation between GAG and sodium values. Color bars on A and B represent MTR $\mathrm{M}_{\text {asym }}$ values summed over offsets from $0-1.3 \mathrm{ppm}$ shifted from water and the sodium signal intensity, respectively (55). 

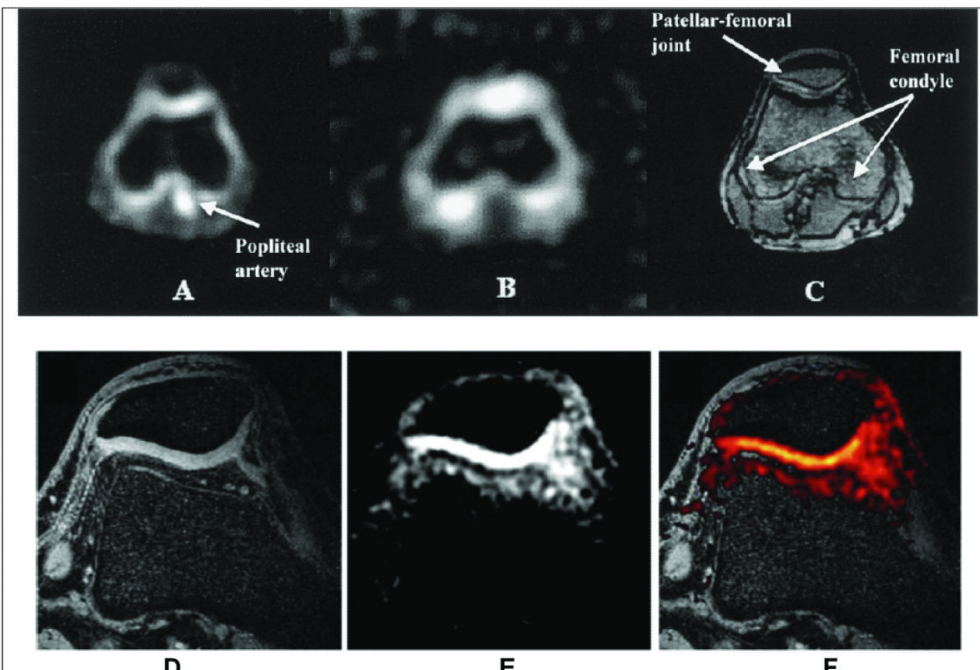

E

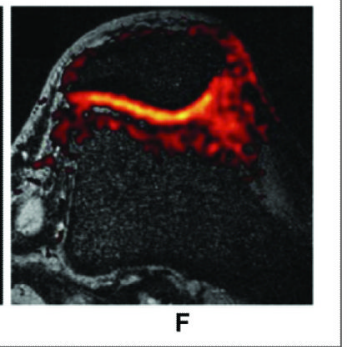

Figure 5.

In vivo (A) single and (B) triple quantum filtered (TQF) ${ }^{23} \mathrm{Na} \mathrm{MR}$ images of the knee of a healthy 27-year-old male volunteer using Twisted Projection Imaging (TPI) obtained on a $3 \mathrm{~T}$ scanner (59). Image $\mathrm{C}$ is the corresponding proton image of the same location. Sodium images were acquired in 10 minutes with a voxel size of $60 \mathrm{cc}$. The arrow in A points to an artery visible in the single quantum image and not visible in the TQF image (B). Proton anatomic Image (D) and high-resolution $\left(1 \times 1 \times 2 \mathrm{~mm}^{3}=6 \mathrm{cc}\right)$ sodium image $(\mathrm{E})$ from the full $3 \mathrm{D}$ volume acquired using 3D Cones sequence on a 7T scanner (73). Overlay of the colormapped sodium image onto the anatomic data (F) shows higher sodium signal in the patellar cartilage than in the subcutaneous region. $7 \mathrm{~T}^{23} \mathrm{Na} \mathrm{MRI}(\mathrm{F})$ shows better delineated cartilage due to a thinner slice and reduced partial volume artifact compared to the image at 3T (A). 